\title{
MÉTODO PEDAGÓGICO MONTESSORIANO CONTEMPORÂNEO E SUAS IMPLICAÇÕES NA EDUCAÇÃO INFANTIL
}

\author{
Astânia Ferreira Pessoa, Universidade Federal de Campina Grande (UFCG), \\ pedag.astaniapessoa@gmail.com
}

\begin{abstract}
RESUMO
A infância é tema, novamente recorrente e sua importância se eleva no tempo presente de necessária revisão dos Parâmetros Curriculares Nacional da Educação Infantil - PCNs e das Diretrizes Curriculares Nacional do Curso de Pedagogia - DCNs. A discussão retoma as tendências pedagógicas e suas correntes para pensar e realizar o processo de ensino e aprendizagem para crianças de zero a seis anos de idade. Nesse cenário, o texto lança questão acerca dos entendimentos de infância e seu processo educacional. Sob a perspectiva da Pedagogia histórico-crítica se discute as contribuições de Maria Montessori à Educação Infantil, bem como seu impacto na contemporaneidade. Apresenta uma revisão da metodologia pedagógica do método montessoriano, como proposta de análise crítica sobre a significação do ser criança e suas diferentes formas de aprender. O objetivo é discutir o impacto do método pedagógico montessoriano a partir do confronto entre diferentes abordagens pedagógicas na literatura. Trata-se de um estudo qualitativo, com pesquisa bibliográfica com uso da análise de dados por meio da tabela de análise de textos acadêmicos e científicos proposta por Novikoff (2010).
\end{abstract}

PALAVRAS-CHAVE: Infância. Método Pedagógico Montessoriano. Formação de Professor.

\section{CONTEMPORARY MONTESSOR PEDAGOGICAL METHOD AND ITS IMPLICATIONS IN EARLY CHILDHOOD EDUCATION}

\begin{abstract}
Childhood is a recurring theme and its importance rises in the present time of a necessary revision of the National Curriculum Parameters of Child Education - PCNs and the National Curricular Guidelines of the Pedagogy Course - DCNs. The discussion resumes the pedagogical tendencies and their currents to think and to realize the process of teaching and learning for children from zero to six years of age. In this scenario, the text launches a question about the understandings of childhood and its educational process. From the perspective of historical-critical pedagogy, Maria Montessori's contributions to Early Childhood Education are discussed, as well as their impact in the contemporary world. It presents a review of the pedagogical methodology of the Montessori method, as a proposal of critical analysis on the meaning of being a child and its different ways of learning. The objective is to discuss the impact of the Montessori teaching method from the confrontation between different pedagogical approaches in literature. This is a qualitative study, with bibliographic research using data analysis through the table of analysis of academic and scientific texts proposed by Novikoff (2010).
\end{abstract}

KEYWORDS: Childhood. Montessorian Pedagogical Method. Teacher Training. 


\title{
MÉTODO PEDAGÓGICO MONTESORIANO CONTREMPORANEO Y SUS IMPLICACIONES EN LA EDUCACIÓN INFANTIL
}

\author{
RESUMEN
}

La infancia es tema, nuevamente recurrente y su importancia se eleva en el tiempo presente de necesaria revisión de los Parámetros Curriculares Nacional de la Educación Infantil - PCNs y de las Directrices Curriculares Nacional del Curso de Pedagogía - DCNs. La discusión retoma las tendencias pedagógicas y sus corrientes para pensar y realizar el proceso de enseñanza y aprendizaje para niños de cero a seis años de edad. En ese escenario, el texto plantea cuestión acerca de los entendimientos de infancia y su proceso educativo. Bajo la perspectiva de la Pedagogía histórico-crítica se discute las contribuciones de María Montessori a la Educación Infantil, así como su impacto en la contemporaneidad. Se presenta una revisión de la metodología pedagógica del método montessoriano, como propuesta de análisis crítico sobre la significación del ser niño y sus diferentes formas de aprender. El objetivo es discutir el impacto del método pedagógico montessoriano a partir del enfrentamiento entre diferentes enfoques pedagógicos en la literatura. Se trata de un estudio cualitativo, con investigación bibliográfica con uso del análisis de datos por medio de la tabla de análisis de textos académicos y científicos propuesta por Novikoff (2010).

PALABRAS CLAVE: Infancia. Método Pedagógico Montessoriano. Formación de profesor.

\section{INTRODUÇÃO}

Pensar as contribuições de Maria Montessori à Educação Infantil, bem como seu impacto na contemporaneidade nos apresenta como temática importante, considerando que sua origem foi para integrar a criança na sociedade de modo humanizado. Assim sendo, apresentar-se-á uma revisão na metodologia pedagógica do método montessoriano, como proposta de análise crítica sobre a significação do ser criança e suas diferentes formas de aprender.

Diante disso questionam-se: quais são os entendimentos de criança e do método montessoriano na literatura vigente? Como são tratados os conceitos de infância e quais são as práticas indicadas para se desenvolver o processo de ensino e de aprendizagem?

O pressuposto a que se estabelece é que apesar do método montessoriano ter sido criado com a proposição de atender aos aspectos humanizadores da educação à época de sua criação, atualmente surgem outras perspectivas, inclusive mercadológicas. 
O presente artigo tem por objetivo discutir o impacto do método pedagógico montessoriano a partir do confronto entre diferentes abordagens pedagógicas na literatura para aferir se há nas propostas uma abordagem sócio-histórica ou técnicista.

Para o desenho da pesquisa adotamos a abordagem dimensional ancorada na proposta de desenvolvimento de pesquisa em Novikoff. Refere-se a uma proposta de ensino de pesquisa, sendo o tempo e o espaço irregular, fractal e impulsionador das atividades a serem realizadas, passando por cinco dimensões de pesquisa.

No que concerne à Dimensão Técnica, nossa pesquisa é de natureza qualitativa, com pesquisa bibliográfica com uso da análise de dados por meio da tabela de análise de textos acadêmicos e científicos proposta por Novikoff (2010).

\section{CONCEPÇÃO DE INFÂNCIA: UM SER HUMANO EM CONSTRUÇÃO}

A compreensão de infância se deu ao longo dos tempos em relativa transformação no contexto histórico da sociedade, bem como nas relações do ser social. Lucas (2005) afirma que as mudanças no conceito de infância não ocorreram por acaso, mas em decorrência da implantação de indústrias, o desenvolvimento da urbanização, marcado pelo êxodo rural, entre outros fatores, pois a criança, nem sempre foi vista e compreendida como um ser em desenvolvimento, com interesses e necessidades próprias. (ARAÚJO, 2005)

A criança sendo então vista como um "adulto em miniatura" trabalhava para ajudar a família, logo, não tinham a compreensão do processo infantil e, por sua vez era uma fase sem importância. Lucas (2005) conceitua a infância da Idade Média como um período de transição para a vida adulta, que deveria ser rapidamente ultrapassado e cuja lembrança também era logo perdida, mas com o avanço das mudanças sociais, relativamente à implantação de grandes indústrias, a mão de obra infantil foi sendo substituída por máquinas, sendo então a criança percebida como um ser que precisava de preparação especializada. Dependente do adulto foi vista como um ser frágil que precisava de cuidados. Sendo assim, creches, escolas maternais e jardins de infância foram surgindo com o intuito de cuidar e proteger as crianças.

[...] Algumas instituições surgem com o objetivo de proteger as crianças. Nessa época surgem três tipos de instituições básicas: as creches, as escolas maternais e os jardins de infância, as quais têm como características 
peculiares o atendimento à criança pequena a partir de iniciativas coletivas que surgem não dos poderes oficiais, mas de iniciativas isoladas, principalmente da igreja. As creches abrigavam crianças pobres e abandonadas. Os jardins de infância tinham o papel de iniciar a parte educativa destinada à classe dominante como complemento da ação familiar. Já as escolas maternais tinham o objetivo de amparar órfãos e filhos de operárias, oferecendo-lhes a guarda e alguma ação educativa. (LUCAS, 2005, p, 82)

Diante do contexto histórico, vê-se que a estrutura familiar também mudou ganhando um novo ordenamento e, por sua vez, novo sentimento de infância - concepção que diferencia a criança do adulto com características próprias no modo de agir e pensar - o que ocasiona preocupação com o desenvolvimento cognitivo da criança a fim de haver uma efetiva preparação da criança para este novo cenário social e, por sua vez a Educação Infantil tem como um de suas principais funções, contribuir com a construção de novos conhecimentos à criança a partir dos conhecimentos previamente adquiridos.

Contudo, a Educação Infantil era entendida como uma instância assistencialista, marcada por transformações na forma de conceber a criança.

A Educação Infantil foi vista como forma de atendimento aos filhos de famílias pobres sendo uma estratégia para combater a pobreza e garantir a sobrevivência dessas crianças e como oportunidade de atuar de forma compensatória para sanar as supostas carências das crianças oriundas da população de baixa renda. (LUCAS, 2005. p. 86)

Vários pensadores com o enfoque de estudar como educar as crianças fez surgir uma demanda de conceitos para melhor desenvolver a educação infantil, dentre eles é relevante destacar os estudos feitos por Maria Montessori, pois atualmente é possível encontrar raízes de seu trabalho nas escolas da sociedade brasileira, em especial, escolas da rede privada, dita montessoriana, como também nas escolas públicas encontramos raízes de seu método em vigor.

Em Montessori, encontramos os fundamentos que fazem com que nos preocupemos em organizar o ambiente escolar utilizando mesas e cadeiras proporcionais ao tamanho das crianças, em mantermos os materiais pedagógicos em prateleiras à altura delas, de termos pias, tanques de lavar roupa, fogões e outros utensílios domésticos em tamanho menores para que elas possam brincar, imitando assim o ambiente familiar. Além disso, ela 
também nos traz reflexões sobre a necessidade de concentração para que algumas atividades possam ser realizadas, enfatizando para tanto a importância do silêncio, e sobre a necessidade das crianças manipularem objetos, utilizando as mãos para isso. Sem falar nos materiais criados por Montessori, presentes em nossas escolas e centros de educação infantil até os dias atuais. (LUCAS, 2005. p. 88-89)

A pedagogia montessoriana vê na criança de hoje o adulto de amanhã e nessa perspectiva o método pedagógico é voltado para a humanização, de modo que a criança se desenvolva na virtude da paz e independência. Como afirma Wajskop (1995), Maria Montessori desenvolveu seu método com base principalmente na observação das crianças, assim ela elaborou uma pedagogia científica que indicava o lúdico, bem como a brincadeira, como uma atividade livre de aprendizagem e espaço educacional.

A criança não é um ser incapaz, frágil e dependente absoluto da atenção do adulto para dirigir sua atividade. Ao contrário, a criança que surge da observação e da teoria que a vê como um ser histórico-cultural é, desde muito pequena, capaz de explorar os espaços e os objetos que encontra ao seu redor, de estabelecer relações com as pessoas, de elaborar explicações sobre os fatos e fenômenos que vivencia. (WAJSKOP, 1995, p. 66)

A atenção e atuação apaixonada de Maria Montessori à ciência da Educação (LAGOA, 1981) são visíveis em sua pesquisa sobre tratamentos empregados em crianças "excepcionais" desenvolvida na Universidade de Roma.

Segundo Lancilloti (2010, p. 5) a proposta pedagógica de Montessori se consolidou fundamentalmente em princípios científicos oriundos da psicologia, sobre os quais desenvolveu nova "organização didática e novos instrumentos de trabalho, buscando formas de contemplar demandas singulares dos alunos".

A pesquisadora buscou compreender as causas de sentimentos de sofrimento de crianças em período da recuperação. Ela observou que as crianças se sentiam tristes, deprimidas e que a sociedade não proporcionava nada além do tratamento médico que também era destinado aos adultos.

Desse modo a trajetória de Maria Montessori iniciada 1899, num Congresso Pedagógico que ocorreu na cidade italiana de Turim, onde a educadora italiana expôs seu trabalho de Educação Moral, ressaltava suas pesquisas e conhecimentos adquiridos de que as crianças "deficientes" não podem ser ignoradas socialmente, mas sim que devem ser 
incluídas, pois o ganho seria para todos. Sendo assim, conseguiu provar com a utilização de seu método de ensino que crianças com problemas mentais poderiam aprender a ler e escrever, assim como qualquer outra criança dita "normal".

\section{PEDAGOGIA MONTESSSORIANA NUM CONTEXTO EDUCACIONAL INFANTIL}

A proposta educacional desenvolvida por Montessori a nível Infantil foi fundada sobre a educação dos sentidos, uma que Maria Montessori considerou que:

[...] a educação dos sentidos tinha enorme importância pedagógica, e que seria a base necessária ao pleno desenvolvimento biológico do indivíduo, sobre o qual se edificaria sua adaptação social. (LANCILLOTI, 2010, p. 167)

Deste modo, compreende-se que a pedagogia montessoriana tem como um dos objetivos, auxiliar o desenvolvimento normal da criança, e não a transmissão de conhecimento como estamos acostumados a presenciar. Contudo, para chegar a esse objetivo, Lancilloti (2010) afirma que a adaptação do ambiente às necessidades e à personalidade dos alunos é de extrema relevância para a obtenção de uma aprendizagem de qualidade, sendo que no ambiente devem ter móveis e objetos simples, práticos e atraentes, que sejam direcionados plenamente à atividade infantil onde os ensinamentos do adulto sejam reduzidos ao mínimo.

Um dos pilares da pedagogia montessoriana é a autoeducação: a criança é livre para escolher as suas atividades conforme suas necessidades (de desenvolvimento) e, assim, educar-se a si mesma na prática das atividades. O que não quer dizer que seja um processo anárquico e desordenado, já que o educador continuará presente, mas será ele o ser passivo frente à atividade desenvolta de seu aluno. (ROSSI, 2015. p. 03)

Nesse sentindo compreende-se que o objetivo da educação de Montessori, como sendo uma educação para a vida, focaliza a autonomia como algo primordial para o desenvolvimento humano, cada pessoa tem a capacidade de aprender por si mesma, desde que haja as condições necessárias. 
A partir de experiência com crianças com problema de saúde mental Montessori ganhou destaque e seu método foi também aplicado a outras crianças, com a utilização de jogos, um dos meios mais eficazes para aquisição de aprendizagem.

[...] o trabalho com jogos em sala de aula também oferece aos alunos desafios genuínos, que vão além do âmbito cognitivo, relacionado diretamente ao dito "conteúdo escolar", gerando interesse e prazer. As crianças, ao depararem com as regras do jogo percebem uma dinâmica grupal, solidária e com finalidades direcionadas. (STAREPRAVO apud GODOY, 2013 p. 5):

Maran apud Godoy (2013) diz que no sistema Montessori, a criança tem muito mais oportunidades de experiências e descobertas pessoais. Nele, a criança encontra muito mais gratificação em suas pesquisas e tarefas, pois o método apresentado por Montessori tem como propósito desenvolver e ativar as energias vitais da criança, de modo que esta possa expressar suas habilidades, uma vez que os materiais usados possibilitam uma liberdade de escolha o que torna o aprender mais atrativo e diversificado.

Neste contexto percebe-se como principal foco da educação, o estudante e não mais o professor como a Pedagogia Tradicional priorizava. Segundo Araújo, Avanzini, Araújo (2005, p. 24) "ao posicionar-se pela atividade da criança, Maria Montessori comunga do ideal da Escola Nova que critica a passividade do aluno da Escola Tradicional e pugna por métodos ativo de aprendizagem".

Diante do contexto apresentado, "ao propor um método educativo em destituir o papel principal do professor e designar o estudante como foco principal da educação, tornou o conceito de aprender de Montessori inovador à sua época" (VILELA, 2014. p. 04)

A compreensão da função de professor como indica Valente, Viana (2009), “O professor deve estar apto para explorar e buscar meios para constante atualização, que propiciem o enriquecimento e renovação dos conhecimentos já adquiridos, mobilizando diversos saberes e uma forma reflexiva de desenvolver a prática docente". Para Estrela, Caetano (2012) é muito marcante o que o professor faz do que o que ele diz sendo necessário haver coerência de discurso e de ação da equipe de professores na escola.

Em referência a pedagogia montessoriana, faz-se necessário uma formação específica de professores para atuarem metodologicamente ao que a pesquisadora italiana propõe. 
[...] não significa que basta colocar na frente de uma criança diversos objetos para que ela passe a compreender determinado conteúdo. O entendimento depende de ações e de atividades que auxiliem a compreensão. Os materiais propostos pela pesquisadora não são uma fórmula mágica que levam o aluno a raciocinar solitariamente; devem-se inserir em situações que permitem ao aluno refletir sobre a experiência que possui. (GODOY, 2013. p. 8)

Diante desse pressuposto compreende-se o quanto o método montessoriano pode continuar sendo úteis as aulas contemporâneas, uma vez que pode torná-las práticas, mais agradáveis e o mais relevante, auxiliando o estudante no desenvolver de suas potencialidades.

Nesse sentido, acreditamos que os estudos no método montessoriano possam nos ajudar a pensar a acolhida de crianças na atualidade, pois tem como princípio a organização dos espaços adequados às crianças, com música e movimento para promover a interação entre crianças. Entre outras práticas o método montessoriano ensina o valor das atividades lúdicas.

É relevante compreender,

O Método Montessoriano é considerado como uma educação para a vida, e suas contribuições são relevantes em diversos pontos, pois ajuda o desenvolvimento natural do ser humano, estimula a criança a formar seu caráter e manifestar sua personalidade, brindando-lhe com segurança e respeito, favorece no aluno a responsabilidade e o desenvolvimento da autodisciplina, ajudando-o para que conquiste sua independência e liberdade, desenvolve na criança a capacidade de participação para que seja aceito, guia a criança na sua formação espiritual e intelectual, reconhece que a criança constrói a si mesma. (OLIVEIRA, BORTOLOTI, 2012, p. 11).

Contudo, é compreensível a necessidade de buscar um conhecimento eficaz sobre o método montessoriano para melhor poder aplicá-lo. Nesse sentido, Oliveira e Bortoloti (2012) enfatizam a expressão "professor montessoriano" definido este como sendo uma pessoa que "observa, estuda, indaga e se deixa indagar, respeita, educa pelo exemplo, é sereno, tem controle de si e de seus impulsos, prepara o ambiente tornando-o atraente e agradável”, sendo assim a criança poderá descobrir sua capacidade de crescer e desenvolver-se; respeitando a si e aos outros, ao mundo, procurando desenvolver o gosto pela ordem, pela organização e pelo silêncio. Deste modo, o professor é um mediador que auxilia no desenvolvimento educacional, cultural e social. Como afirma Araújo (2005) o professor deve ser um 
profissional com uma visão holística capaz de compreender como a criança se desenvolve e aprende; é relevante que seja um mediador das interações entre as crianças.

Assim sendo o professor precisa compreender que o material a ser utilizado e adotado de acordo o método montessoriano dever servir como instrumento para a educação, sendo apenas um elemento de ligação entre a criança e o currículo.

O objetivo não está no material nem no currículo, mas sim na criança como pessoa, desenvolvendo as suas potencialidades, a sua linguagem. No cotidiano, o adulto costuma facilitar as coisas para as crianças - quando não faz as coisas por ela. Para o Método Montessori o material é um elemento que carrega uma proposta: a reflexão. Acriança tem que pensar para usá-lo, para conquistá-lo. (ALMEIDA, 1984, p. 11)

O método Montessori tem seu destaque na atuação do professor e de sua mínima intervenção para ajudar o aluno a extenuar suas habilidades, pois esse é um dos meios mais eficazes para perceber a capacidade do aluno, o desenvolvimento da aprendizagem e assim, garantir uma qualidade de ensino que abrange as diversas áreas da aprendizagem, para tanto a Carvalho, Carvalho (2010) ressalta que a pedagogia montessoriana defini o papel do professor, a partir da observação ás crianças, como o organizador do ambiente, aquele que facilita as atividades.

\section{RESULTADO}

\section{TABELAS E DESCRIÇÃO TEXTUAL DAS MESMAS}

\begin{tabular}{|c|c|c|c|c|c|}
\hline AUTOR & INFÂNCIA & MÉTODO & PROFESSOR & HUMANISTA & TECNICISTA \\
\hline $\begin{array}{c}\text { LUCAS } \\
\text { (2005) }\end{array}$ & $\begin{array}{l}\text { A infância da idade média era } \\
\text { compreendida como um período de } \\
\text { transição para a vida adulta, que } \\
\text { deveria ser rapidamente ultrapassado } \\
\text { e cuja lembrança também era logo } \\
\text { perdida. }\end{array}$ & $\begin{array}{l}\text { Abordagem } \\
\text { Qualitativa }\end{array}$ & & & $X$ \\
\hline $\begin{array}{c}\text { WAJSKOP } \\
(1995)\end{array}$ & $\begin{array}{l}\text { A criança não é um ser incapaz, frágil } \\
\text { e dependente absoluto da atenção do } \\
\text { adulto para dirigir sua atividade. Ao } \\
\text { contrário, a criança que surge da } \\
\text { observação e da teoria que a vê como } \\
\text { um ser histórico-cultural é, desde } \\
\text { muito pequena, capaz de explorar os } \\
\text { espaços e os objetos que encontra ao } \\
\text { seu redor, de estabelecer relações com } \\
\text { as pessoas, de elaborar explicações }\end{array}$ & $\begin{array}{l}\text { Abordagem } \\
\text { Qualitativa }\end{array}$ & & $\mathrm{X}$ & \\
\hline
\end{tabular}




\begin{tabular}{|c|c|c|c|c|c|}
\hline & $\begin{array}{l}\text { sobre os fatos e fenômenos que } \\
\text { vivencia. }\end{array}$ & & & & \\
\hline $\begin{array}{l}\text { ROSSI } \\
(2015)\end{array}$ & $\begin{array}{l}\text { A criança é livre para escolher as suas } \\
\text { atividades conforme suas } \\
\text { necessidades (de desenvolvimento) e, } \\
\text { assim, educar-se a si mesma na prática } \\
\text { das atividades. O que não quer dizer } \\
\text { que seja um processo anárquico e } \\
\text { desordenado, já que o educador } \\
\text { continuará presente, mas será ele o ser } \\
\text { passivo frente à atividade desenvolta } \\
\text { de seu aluno. }\end{array}$ & $\begin{array}{l}\text { Abordagem } \\
\text { Qualitativa }\end{array}$ & & $X$ & \\
\hline $\begin{array}{c}\text { ARAÚJO } \\
(2005)\end{array}$ & & $\begin{array}{l}\text { Abordagem } \\
\text { Qualitativa }\end{array}$ & $\begin{array}{l}\text { Um profissional que tenha uma } \\
\text { visão mais holística de como a } \\
\text { criança se desenvolve e aprende; } \\
\text { que seja um mediador das } \\
\text { interações entre as crianças. }\end{array}$ & $X$ & \\
\hline $\begin{array}{l}\text { OLIVEIRA, } \\
\text { BORTOLOTI } \\
\text { (2012) }\end{array}$ & $\begin{array}{l}\text { Para montessori a criança é } \\
\text { compreendida como um ser capaz de } \\
\text { crescer por si mesmo e aprender } \\
\text { naturalmente com o auxílio de } \\
\text { orientações adequadas e no momento } \\
\text { preciso; é um ser que difere do adulto, } \\
\text { apresentando necessidades próprias, } \\
\text { original e único }\end{array}$ & $\begin{array}{l}\text { Abordagem } \\
\text { Qualitativa }\end{array}$ & $\begin{array}{l}\text { Professor montessoriano - } \\
\text { observa, estuda, indaga e se deixa } \\
\text { indagar, respeita, educa pelo } \\
\text { exemplo, é sereno, tem controle } \\
\text { de si e de seus impulsos, prepara } \\
\text { o ambiente tornando-o atraente e } \\
\text { agradável. }\end{array}$ & $X$ & \\
\hline $\begin{array}{l}\text { CARVALHO, } \\
\text { CARVALHO } \\
\text { (2010) }\end{array}$ & & $\begin{array}{l}\text { Abordagem } \\
\text { Qualitativa }\end{array}$ & $\begin{array}{l}\text { Em sua pedagogia, Montessori } \\
\text { definiu o papel da responsável } \\
\text { pelas crianças - a mestra - como } \\
\text { organizadora do ambiente e } \\
\text { facilitadora das atividades a partir } \\
\text { da observação do grupo. }\end{array}$ & $X$ & \\
\hline $\begin{array}{l}\text { VALENTE, } \\
\text { VIANA } \\
(2009)\end{array}$ & & $\begin{array}{l}\text { Abordagem } \\
\text { Qualitativa }\end{array}$ & $\begin{array}{l}\text { O professor deve estar apto para } \\
\text { explorar e buscar meios para } \\
\text { constante atualização, que } \\
\text { propiciem o enriquecimento e } \\
\text { renovação dos conhecimentos já } \\
\text { adquiridos, mobilizando diversos } \\
\text { saberes e uma forma reflexiva de } \\
\text { desenvolver a prática docente. }\end{array}$ & & $\mathrm{X}$ \\
\hline $\begin{array}{l}\text { ESTRELA, } \\
\text { CAETANO } \\
(2012)\end{array}$ & & $\begin{array}{l}\text { Abordagem } \\
\text { Qualitativa }\end{array}$ & $\begin{array}{l}\text { O professor é um modelo ou anti } \\
\text { modelo para o aluno. Por isso, é } \\
\text { mais marcante o que ele faz do } \\
\text { que o que ele diz e que deve } \\
\text { haver coerência de discurso e de } \\
\text { ação da equipe de professores na } \\
\text { escola, considerada como um } \\
\text { todo. }\end{array}$ & & $X$ \\
\hline
\end{tabular}

A tabela de análise das Dimensões de Pesquisa propostas Por Novikoff (2010) TABDN - proporciona o aprofundamento e revisão dos textos contribuindo no enriquecimento da elaboração de trabalhos científicos.

É, portanto, um instrumento tecnológico que intensifica a leitura analítica e crítica de textos proporcionando melhor aprendizagem.

Deste modo, dos artigos indicados na tabela acima ao serem analisados pela TABDN foram extraídos alguns conceitos sobre infância e professor, o que nos remete a compreensão de que alguns apresentam conceitos de caráter humanista enquanto que outros apresentam 
conceitos de caráter tecnicista, sem considerar os aspectos socio-histórico da formação da criança.

Conceitos humanistas aproximam-se da pedagogia montessoriana, uma vez que a pesquisadora Maria Montessori tinha como um de seus objetivos uma educação para a vida, de modo que a criança pudesse se desenvolver livremente acreditando na paz e na capacidade da transformação do mundo. Por sua vez, os conceitos tecnicistas apresentam-se como a imposição de uma regra, uma fórmula a ser seguida, é uma indicação ao método de trabalho que o professor deve seguir.

\section{CONCLUSÃO}

A discussão que se estabelece sobre a pedagogia montessorina a partir do confronto entre diferentes concepções pedagógicas apresentadas na literatura analisada remete-nos uma visão crítica sobre o ensino no momento contemporâneo histórico-social na medida em que vivenciamos grandes conflitos e avanço tecnológico, diante disso caracterizamos como relevante para o processo da aprendizagem o aprofundamento no conhecimento sobre o método montessoriano, pois como já discutido, este traz inovações significativas para a vida da criança, por se tratar de uma pedagogia que valoriza o potencial, bem como sua capacidade de se autoeducar.

Logo, a cultura de paz, a disciplina, a liberdade e autonomia - características do método Montessori - são contributos essenciais na vida adulta do ser humano. 


\section{REFERÊNCIAS}

ALMEIDA, Talita de. Montessori: o tempo o faz cada vez mais atual. Perspectiva; $r$ CEV, Florianópolis, 1(2), 9-19. Jan./Jun. 1984.

ARAÚJO Alberto Filipe; AVANZINI Alessandra; ARAÚJO Joaquim Machado de Actividade e Redenção - A Criança Nova em Maria Montessori. História da Educação, ASPHE/FaE/UFPel, Pelotas, n. 18, p. 23-45, set. 2005.

ARAÚJO, Regina Magna Bonifácio de. A formação dos professores para a educação infantil: novos olhares. Revista de Educação do Cogeime A n o 14 - n. 27 - dezembro / 2005.

CARVALHO, Denise Maria de.; CARVALHO, Tânia Câmara Araújo de EDUCAÇÃO INFANTIL: história, contemporaneidade e formação de professores. (2010) Disponível em <file:///C:/Users/Familia/Downloads/met+ed+inf.PDF > Acesso em: 04 de agosto de 2017

ESTRELA, Maria Teresa; CAETANO, Ana Paula. REFLEXÕES SOBRE A FORMAÇÃO ÉTICA INICIAL DE PROFESSORES. 2012. Disponível em <http://revistas.rcaap.pt/interaccoes/article/view/1532> Acesso em: 04 de agosto de 2017

GODOY, Ana Maria. Os materiais idealizados por Montessori para uma aprendizagem significativa. I Seminário da ANPAE. 2013.

LAGOA, V. Estudo do sistema Montessori: fundamentado na análise experimental do comportamento. São Paulo: Loyola, 1981.

LANCILLOTTI Samira Saad Pulchério. PEDAGOGIA MONTESSORIANA: ensaio de individualização do ensino Revista HISTEDBR On-line, Campinas, número especial, p. 164-173, mai.2010.

LUCAS, Maria Angélica Olivo Francisco. EDUCAÇÃO INFANTIL: algumas reflexões sobre seus fundamentos teóricos e metodológicos. Revista HISTEDBR On-line, Campinas, n.17, p. 79 - 90 mar. 2005.

OLIVEIRA, Kely Viviane Gonçalves de.; BORTOLOTI, Roberta DeAngela Menduni MÉTODO MONTESSORIANO: contribuições para o ensino-aprendizagem da matemática nas séries iniciais. Revista Eventos Pedagógicos v.3, n.3, p. 410 - 426 Ago. - Dez. 2012.

ROSSI, Aline dos Santos. DIÁLOGOS DE UMA EDUCAÇÃO LIBERTADORA: de Montessori A Paulo Feire. 2015. Disponível em <http://acervo.paulofreire.org:8080/jspui/bitstream/7891/4293/1/FPF_PTPF_01_0942.pdf> acesso em 25/01/2007 
VALENTE, Geilsa Soraia Cavalcanti; VIANA, Ligia de Oliveira. Da formação por competências à prática docente reflexiva. Revista Iberoamericana de Educación ISSN: 1681-5653 n. ${ }^{\circ} 48 / 4$ - 10 de febrero de 2009.

VILELA, Silvio Henrique. MARIA MONTESSORI: O caminho dos sentidos. Revista Teias v. $15 \cdot$ n. $38 \cdot 32-46 \cdot 2014$

WAJSKOP, Gisela. O brincar na educação infantil. CAD. Pesq. São Paulo, n. 92, p. 62-69, fev. 1995. 